\title{
MATHEMATICAL METHODS IN QUEUEING THEORY
}

\author{
Kluwer Academic Publishers, Amsterdam, 1994 (to appear) \\ VLADIMIR V. KALASHNIKOV \\ Institute of Systems Analysis, \\ 9, Prospect 60 let Oktyabrya, \\ 117312 Moscow, Russia \\ e-mail:mconeau@glas.apc.org \\ fax: (095) 938-2209
}

The book treats systematically the basic mathematical tools relevant for studying queueing models. It includes both traditional and completely new results that emphasize obtaining not only explicit formulas but also quantitative bounds for characteristics of interest. This predetermines a usage of modern techniques, such as wide sense regenerative processes, the test functions method for studying denumerable and general Markov chains, probability metrics, the coupling method and other techniques which are not usually treated in standard textbooks. The following topics make this book unique among others with similar titles:

- classification of denumerable and general Markov chains and their application to studying single-server, multi-server and multi-phase queueing models;

- introduction and study of a class of general Markov chains induced by piecewise-linear transforms which serve as models of various queueing systems;

- continuity (comparison) estimates for wide sense regenerative processes and for numerous queueing models;

- estimates of the rate of convergence to the steady state for single-server, multi-server and multi-phase queueing models;

- metric and two-side bounds on the distribution function of the first breakdown time for reliability models.

The material in the book is well organized and provides many examples and problems. It can be used at an entry and advance level graduate courses. The book is also intended for applied probabilists, operations researchers, and engineers who specialize in telecommunications and computer science. 


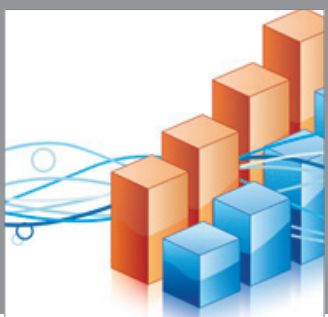

Advances in

Operations Research

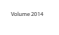

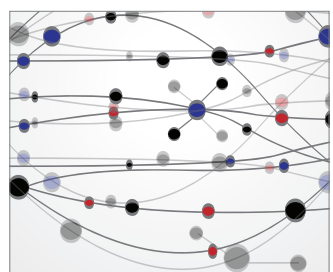

\section{The Scientific} World Journal
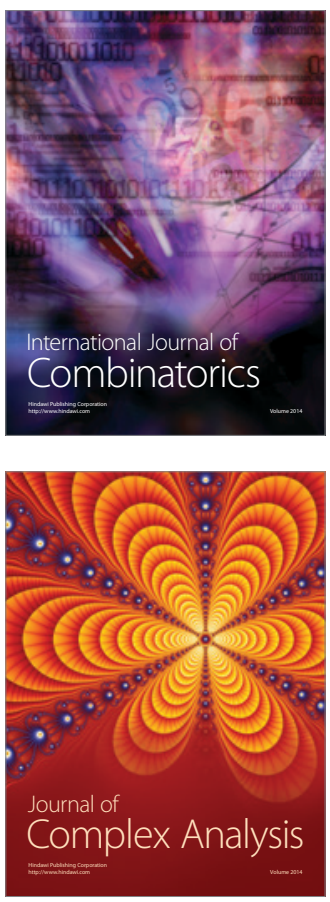

International Journal of

Mathematics and

Mathematical

Sciences
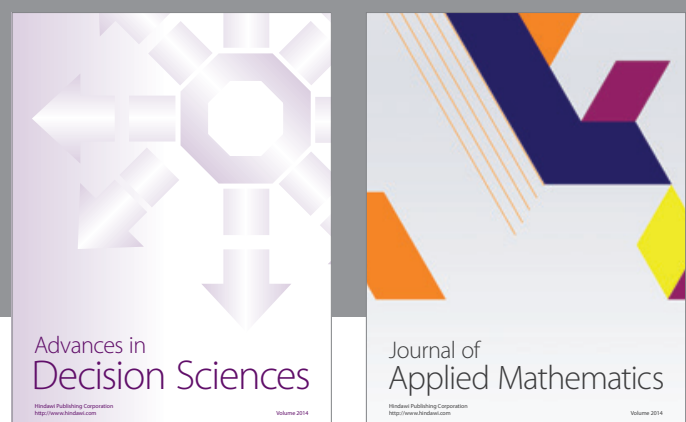

Journal of

Applied Mathematics
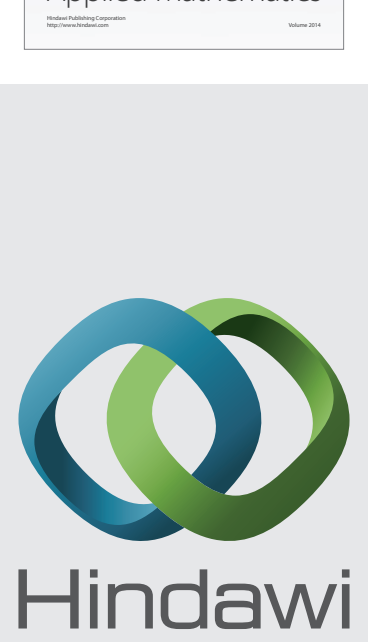

Submit your manuscripts at http://www.hindawi.com
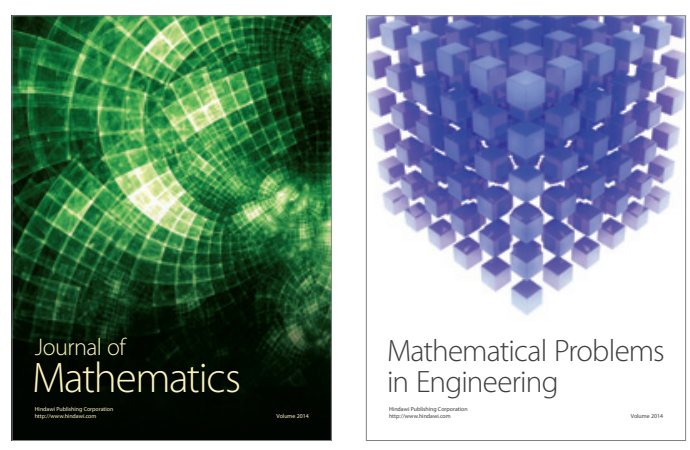

Mathematical Problems in Engineering
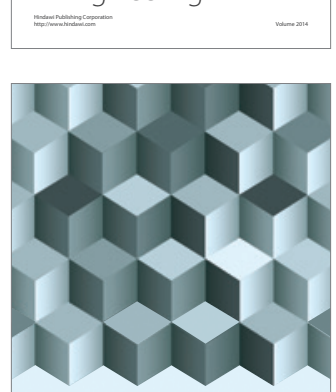

Journal of

Function Spaces
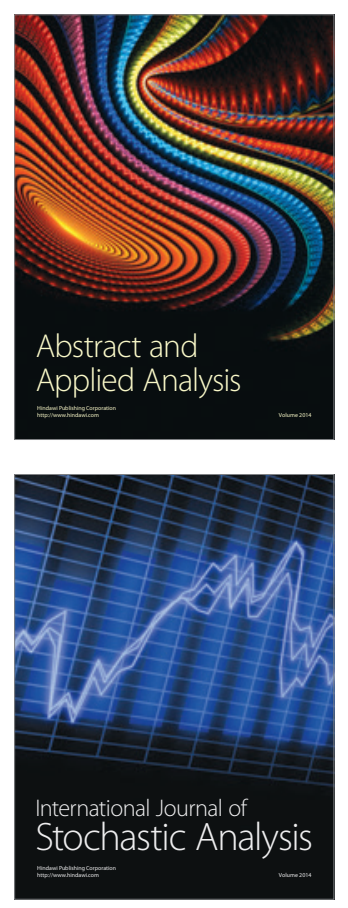

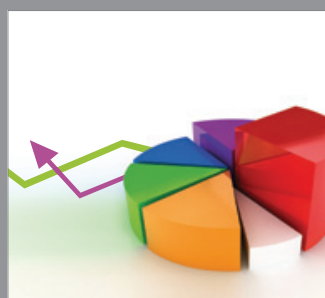

ournal of

Probability and Statistics

Promensencen
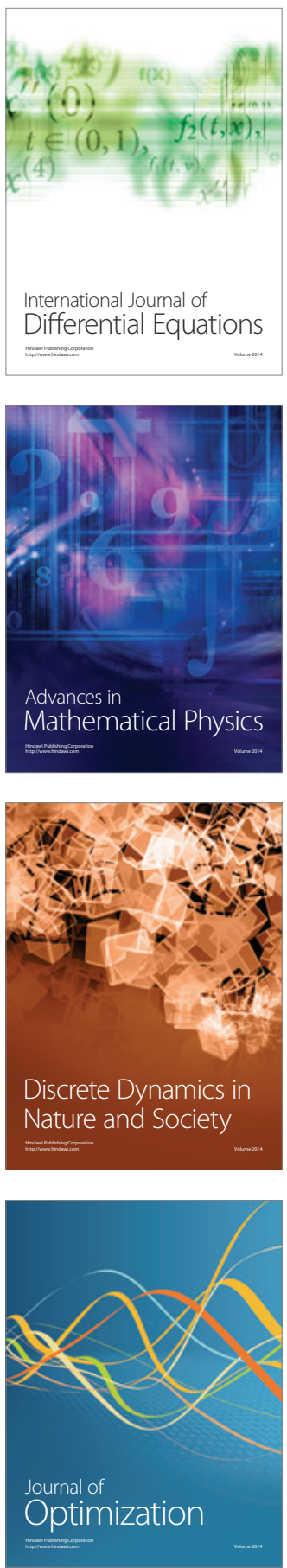